\title{
Quantification of Lysosomal Membrane Permeabilization by Cytosolic Cathepsin and $\beta$-N-Acetyl-Glucosaminidase Activity Measurements
}

\author{
Marja Jäättelä and Jesper Nylandsted ${ }^{1}$ \\ Unit for Cell Death and Metabolism, Center for Autophagy, Recycling and Disease, Danish Cancer Society \\ Research Center, DK-2100, Copenhagen, Denmark
}

Programmed cell death involving lysosomal membrane permeabilization (LMP) is an alternative cell death pathway induced under various cellular conditions and by numerous cytotoxic stimuli. The method presented here to quantify LMP takes advantage of the detergent digitonin, which creates pores in cellular membranes by replacing cholesterol. The difference in cholesterol content between the plasma membrane (high) and lysosomal membrane (low) allows titration of digitonin to a concentration that permeabilizes the plasma membrane but leaves lysosomal membranes intact. The extent of LMP is determined by measuring the cytosolic activity of lysosomal hydrolases (e.g., cysteine cathepsins) and/or $\beta$ - $N$-acetyl-glucosaminidase in the digitonin-extracted cytoplasm and comparing it to the total cellular enzyme activity. Digitonin extraction of the cytosol can be combined with precipitation of protein and/or western blot analysis for detection of lysosomal proteins (e.g., cathepsins).

MATERIALS

It is essential that you consult the appropriate Material Safety Data Sheets and your institution's Environmental Health and Safety Office for proper handling of equipment and hazardous materials used in this protocol.

RECIPES: Please see the end of this protocol for recipes indicated by $<R>$. Additional recipes can be found online at http://cshprotocols.cshlp.org/site/recipes.

Reagents

$\beta$ - $N$-acetyl-glucosaminidase reaction buffer $(\mathrm{NAG} \mathrm{RB})<\mathrm{R}>$

Caspase reaction buffer (caspase RB), freshly prepared (optional; see Step 14) $<\mathrm{R}>$

Caspase-3 activity can be measured simultaneously (on the same plate) with cathepsin activity, provided that the substrates are coupled to the same fluorophore (e.g., Ac-DEVD-7-amino-trifluoromethylcoumarin [AFC]), but this measurement is not required for analysis of lysosomal membrane permeabilization (LMP).

Cathepsin reaction buffer (cathepsin $\mathrm{RB}$ ), freshly prepared $<\mathrm{R}>$

Cell line of interest and appropriate growth medium

The current protocol has been tested on various cell lines treated with a range of different cytotoxic stimuli and works well for most standard cancer cell lines (including MCF-7, HeLa, and U2OS) using the following conditions: 15 min extraction, lifting frequency 50-60/min, digitonin concentration 15-25 $\mu \mathrm{g} / \mathrm{mL}$ (Foghsgaard et al. 2001; Nylandsted et al. 2004; Groth-Pedersen et al. 2007). However, the optimal extraction time and lifting frequency

\footnotetext{
${ }^{1}$ Correspondence: jnl@cancer.dk

(c) 2015 Cold Spring Harbor Laboratory Press

Cite this protocol as Cold Spring Harb Protoc; doi:10.1101/pdb.prot086165
} 
M. Jäättelä and J. Nylandsted

may differ for other cell lines and should be determined empirically. For example, immortalized mouse embryonic fibroblasts (MEFs) are processed as follows: 10 min extraction, lifting frequency 110/min, digitonin concentration $17 \mu \mathrm{g} / \mathrm{mL}$ (Gyrd-Hansen et al. 2006).

Cytotoxic agent (compound or siRNA) for induction of LMP

Digitonin extraction (DE) buffer, freshly prepared $<\mathrm{R}>$

For digitonin optimization (Step 2) and subsequent measurement of LMP (Step 10), prepare $200 \mu L$ of DE buffer per well (plus an additional $20 \mu \mathrm{L}$ to adjust for pipetting loss). (This volume can be scaled up accordingly for larger well formats [e.g., six-well plates].)

Digitonin stocks (5 and $50 \mathrm{mg} / \mathrm{mL}$ in $\mathrm{H}_{2} \mathrm{O}$ )

Digitonin usually precipitates and must be redissolved by heating and occasional vortexing. Immediately before use (Step 2), heat the digitonin stocks to $75^{\circ} \mathrm{C}$ for 5-10 min to dissolve any precipitates.

$\mathrm{HCl}(1 \mathrm{M})$

LDH cytotoxicity detection kit (Roche or similar)

Total protein assay kit (if needed; see Step 16)

\section{Equipment}

Absorbance plate reader (e.g., VersaMax; Molecular Devices)

Incubator for cell culture

Microwell plates, black (96-well)

Rocking table with adjustable lifting frequency

Spectrofluorometer (e.g., Spectramax Gemini; Molecular Devices)

Tissue culture plates (24- and 96-well)

Vacuum suction pump

\section{METHOD}

\section{Determining Optimal Digitonin Concentration for Extraction of Lysosome-Free Cytoplasm}

The following procedure is necessary to determine the optimal digitonin concentration for permeabilization of the plasma membrane with minimal impact on the lysosomal membrane. LDH activities in the extracts are used as internal standards to which the lysosomal hydrolase activities are normalized. The procedure takes $\sim 1 \mathrm{~h}$ and must be performed for each cell line separately. It should be performed regularly, as reagents (e.g., digitonin stocks) and cellular conditions may change over time.

Note that the ability of digitonin to permeabilize cellular membranes depends not only on digitonin concentration but also on the total amount of digitonin per cell; thus, the volume of DE buffer per cell should remain constant.

1. Seed $5 \times 10^{4}$ cells/well in a 24-well plate and allow to adhere overnight in an incubator.

At least 12 wells should be used for the optimization.

LMP can also be measured in nonadherent cells; in this case, it is advantageous to scale down the cell number and seed cells in 96-well rather than 24-well plates to prevent cells from floating.

2. On the next day (immediately before use), prepare the following 12 dilutions of digitonin in $\mathrm{DE}$ buffer: $0,5,10,15,20,25,30,35,40,45,50$, and $200 \mu \mathrm{g} / \mathrm{mL}$ digitonin.

A digitonin solution of $200 \mu \mathrm{g} / \mathrm{mL}$ is used for total/complete permeabilization of cells.

3. Place the plate on ice and begin the extraction as follows:

i. Working with sets of six wells at a time, remove the medium from each well using a vacuum suction pump. (If using nonadherent cells, carefully aspirate the medium from the wells and leave $\sim 20 \mu \mathrm{L}$ of medium on the cells.)

Wells should be processed six at a time to prevent the cells from drying out when medium is removed.

ii. Add $200 \mu \mathrm{L}$ of one digitonin dilution to each well. Start a timer when digitonin is added to each set of six wells.

The digitonin solution should be added to the side of the well to avoid flushing off the attached cells.

Exact timing is critical to ensure that each well is extracted equally. 
4. Incubate the cells on ice for $15 \mathrm{~min}$ on a rocking table (lifting frequency $\sim 50-60 / \mathrm{min}$ ).

5. Transfer $180 \mu \mathrm{L}$ of each extract into one well of a labelled 96-well plate on ice.

6. Perform the cathepsin assay as follows:

i. Mix $50 \mu \mathrm{L}$ of extract with $50 \mu \mathrm{L}$ of cathepsin $\mathrm{RB}$ in one well of a black 96-well plate.

ii. Preincubate the plate for $5 \mathrm{~min}$ at $30^{\circ} \mathrm{C}$ in the fluorometer.

iii. Measure the kinetics of cathepsin activity (i.e., the $V_{\max }$ of the liberation of AFC) for $20 \mathrm{~min}$ at $30^{\circ} \mathrm{C}$ (excitation, $400 \mathrm{~nm}$; emission, $489 \mathrm{~nm} ; 45 \mathrm{sec}$ interval).

7. During the cathepsin assay, perform the LDH assay as follows:

i. Transfer $30 \mu \mathrm{L}$ of extract per well to a 96 -well plate and equilibrate to room temperature for 5-10 min.

ii. Add $30 \mu \mathrm{L}$ of mixed $\mathrm{LDH}$ reagent to each well and allow the reaction to run for 2-10 min. Stop each reaction with $20 \mu \mathrm{L}$ of $1 \mathrm{M} \mathrm{HCl}$.

Make sure all samples have equal reaction time before ending the reaction, typically when the samples with highest $L D H$ content are medium to intense red.

iii. Assay LDH activity by measuring the optical density (OD) $490 \mathrm{~nm}\left(\mathrm{OD}_{490}\right)$ in an absorbance plate reader.

8. To determine the optimal digitonin concentration for cytosolic extraction, graph and compare the cathepsin release and LDH raw values (Fig. 1).

The concentration that produces the best possible permeabilizion of the plasma membrane (LDH release) with minimal cathepsin release from the lysosomes is optimal.

In the following procedure, the level of LMP in response to a given treatment is measured by digitonin extraction of the cytoplasmic fraction followed by hydrolase and/or NAG activity measurements. Measurement of LMP by digitonin extraction takes 2-3 h for two 24-well plates.

9. For each cellular condition (e.g., treatment with siRNA or cytotoxic compound), seed cells in triplicate wells of a 24-well plate. Seed parallel triplicate wells for total cellular cathepsin measurements (Fig. 2A).
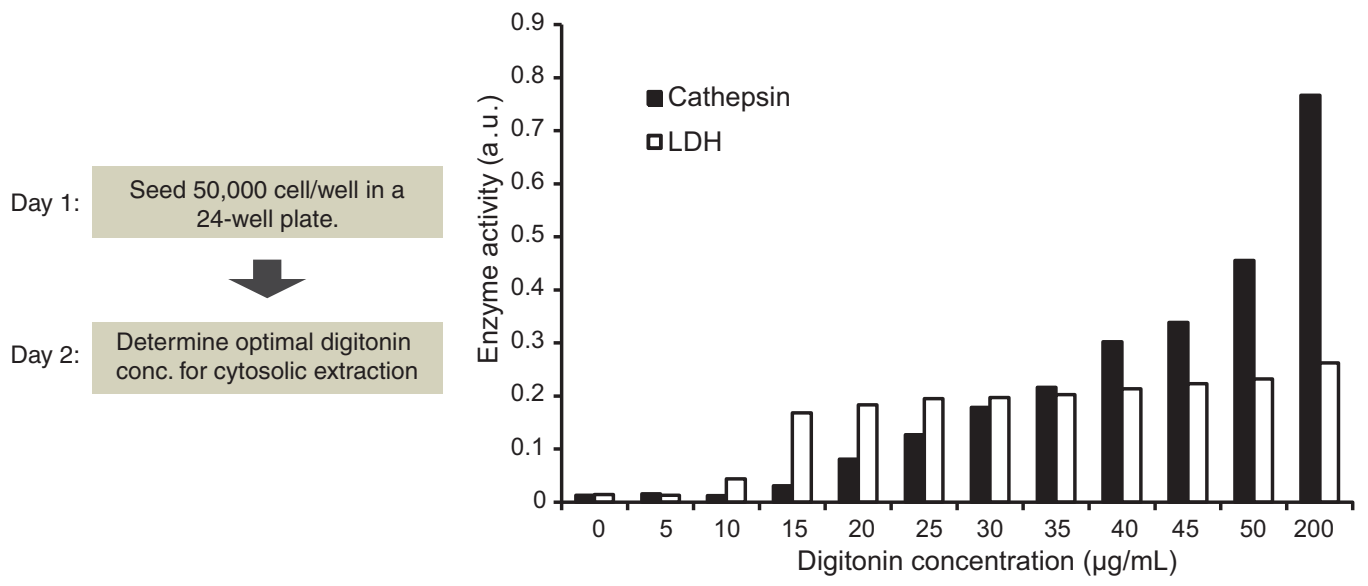

FIGURE 1. Example of optimization experiment used to determine the digitonin concentration to be used for cytoplasmic extraction of MCF-7. Cells $\left(5 \times 10^{4}\right.$ per well) were extracted for $15 \mathrm{~min}$ on a rocking table (lifting frequency $50-60 / \mathrm{min}$ ) with the indicated digitonin concentrations. The level of plasma membrane permeabilization (LDH activity) and lysosome permeabilization (cathepsin activity) were measured. Cells were completely permeabilized at $200 \mu \mathrm{g} / \mathrm{mL}$ digitonin (total). A digitonin concentration that only permeabilizes the plasma membrane and leaves lysosomes intact is ideal. Here, $15-18 \mu \mathrm{g} / \mathrm{mL}$ is optimal for MCF-7 cells. 
M. Jäättelä and J. Nylandsted

Cells should be seeded at a density that will on the day of analysis result in the density used in the digitonin optimization experiment (e.g., $\sim 5 \times 10^{4}$ cells).

10. On the day of analysis (immediately before use), prepare digitonin solutions in DE buffer for cytoplasmic extraction (using the optimal concentration obtained in Step 8) and total cell extraction.

In our laboratory, we use digitonin solutions of $17 \mu \mathrm{g} / \mathrm{mL}$ and $200 \mu \mathrm{g} / \mathrm{mL}$, respectively, for cytoplasmic and total cell extractions in MEF. See Figure 1, for example, using MCF-7 cells.

11. Place the plate on ice and begin the digitonin extraction as described in Step 3. Mark the time of digitonin addition on the plate lid for each set of six wells.

Swift pipetting is necessary to avoid too much variation among wells.

12. Incubate the plate on ice for $15 \mathrm{~min}$ on a rocking table (lifting frequency $\sim 50-60 / \mathrm{min}$ ).

The optimal time and lifting frequency may vary between cell lines.

13. Transfer $180 \mu \mathrm{L}$ of each extract into one well of a labelled 96-well plate on ice.

The cytoplasmic/total extracts can now be used to measure lysosomal cysteine cathepsin, NAG, LDH, and caspase 3-like activities.

A

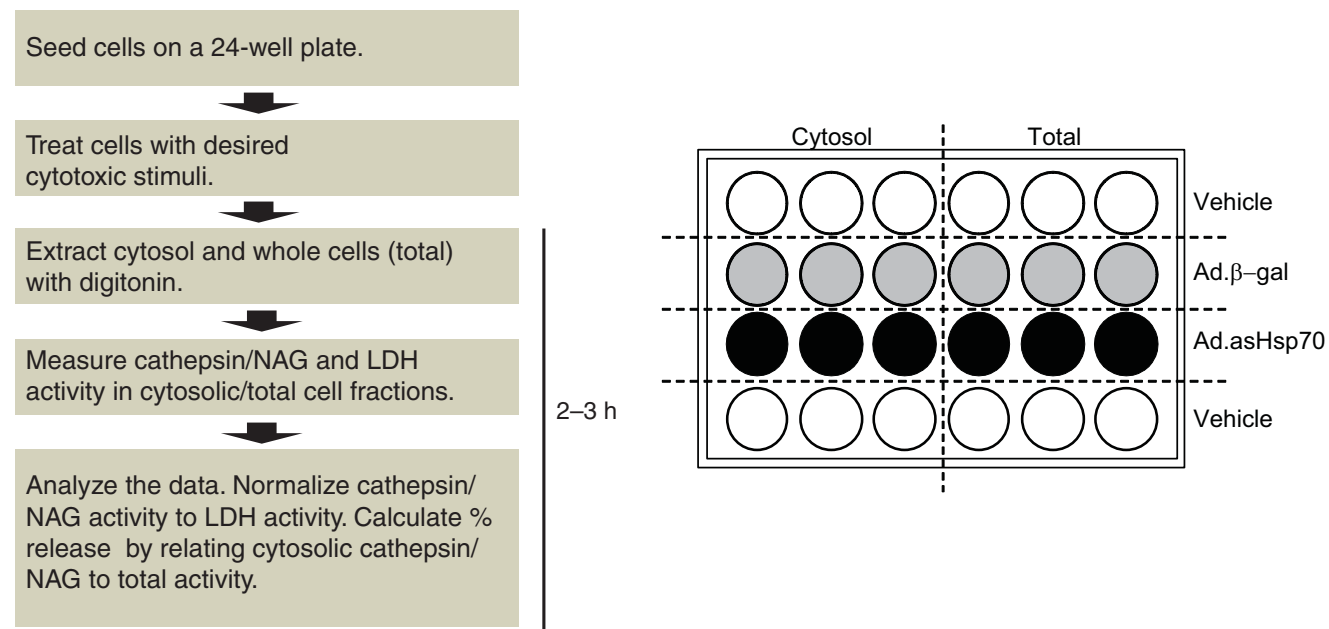

B

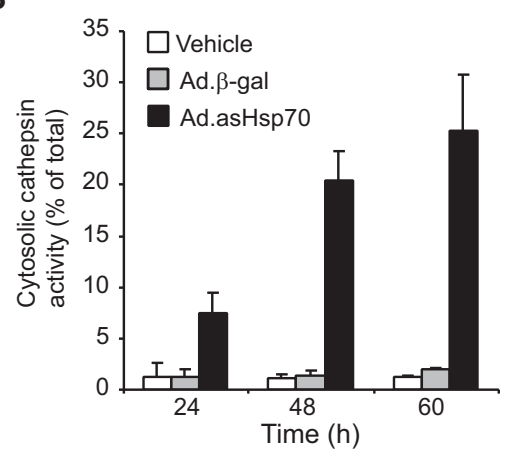

C

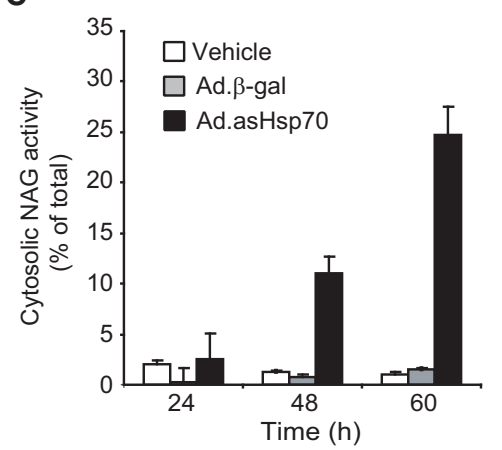

FIGURE 2. (A) Flowchart of the digitonin extraction procedure for measuring LMP. Sample LMP extraction setup in a typical 24-well format with vehicle control, $\beta$-galactosidase adenovirus control (Ad. $\beta$-gal) or adenovirus containing antisense Hsp70 cDNA (Ad.asHsp70) as the LMP inducer. Cells are seeded in triplicate for both cytosolic and total cellular extraction, and digitonin is added to sets of six wells and timed to ensure all wells are extracted equally. $(B) \mathrm{A}$ representative example of lysosomal cathepsin B/L release and (C) NAG release obtained from MCF-7 cells transduced for 24-60 h with Ad.asHsp70, which depletes Hsp70 and triggers LMP. Values are normalized to LDH and presented as \% cytosolic release of total cellular cathepsin or NAG activity. Numbers represent mean of triplicate measurements and error bars indicate SD values (C Nylandsted et al. 2004. Originally published in J Exp Med 200: 425-435.) 
Data Analysis

14. Perform cathepsin and caspase-3 assays as follows:

i. Mix $50 \mu \mathrm{L}$ of extract with $50 \mu \mathrm{L}$ of cathepsin RB per well in a black 96-well plate.

ii. (Optional) Mix $50 \mu \mathrm{L}$ of extract with $50 \mu \mathrm{L}$ of caspase RB per well in the same black 96-well plate.

iii. Preincubate the plate for $5 \mathrm{~min}$ at $30^{\circ} \mathrm{C}$ in the fluorometer.

iv. Measure as described in Step 6.iii.

Cathepsin (and caspase) activity in cytosolic and total extracts is calculated as the average rate (slope of the curve; fluorescence units/sec).

15. Measure lysosomal NAG release as follows:

i. Mix $30 \mu \mathrm{L}$ of extract with $100 \mu \mathrm{L}$ of NAG RB per well in a black 96-well plate.

ii. Preincubate the plate for $3-5 \mathrm{~min}$ at $30^{\circ} \mathrm{C}$ in the fluorometer.

iii. Measure the liberation of methylumbelliferone for $20 \mathrm{~min}$ at $30^{\circ} \mathrm{C}$ (excitation, $356 \mathrm{~nm}$; emission, $444 \mathrm{~nm} ; 45 \mathrm{sec}$ interval).

NAG activity in extracts is calculated as the average rate (slope of the curve; fluorescence units/sec).

16. Perform the LDH assay for each well as described in Step 7.

If the treatment of the cells alters the cellular LDH activity, hydrolase activities can be normalized to total protein content using a commercial kit designed for this purpose.

17. Normalize each lysosomal hydrolase/NAG value to the corresponding LDH value from the same well (Fig. 2A).

See Troubleshooting.

18. Calculate the mean values of the triplicate measurements for cytoplasmic and total protease levels (Fig. 2A).

19. Calculate the percentage of released enzyme activity by relating the LDH-corrected cytoplasmic activity of the lysosomal hydrolase/NAG measured for each well with the mean value from triplicate samples for corresponding total cellular activity of the hydrolase/NAG (Fig. 2B,C).

See Troubleshooting.

Problem (Step 17): Digitonin overextraction results in high cathepsin/NAG background levels $(>10 \%)$.

Solution: This is a common difficulty associated with LMP measurements and can be adjusted by further fine-tuning the digitonin extraction (e.g., by using a narrower range of digitonin concentrations during optimization to determine an optimal lower concentration). In addition, cell density is critical to achieving the best digitonin:cell ratio for cytoplasmic extraction; this can be optimized by keeping the digitonin concentration constant and varying the cell density. Finally, optimization of extraction time may be helpful with some cell types.

Problem (Step 17): Because of the shorter half-life of cathepsins in the cytosol as compared with the lysosome, the obtained values are, in fact, lower than the actual release of the hydrolases.

Solution: This may especially become a problem in long-term experiments and should be considered if the total cathepsin/LDH ratios decline extensively. The cytosolic half-life of NAG is longer than that of cathepsins and thus NAG measurements can give more accurate values in long-term assays. Additionally, determining the kinetics of the LMP by multiple measurements at different time points after the stimulus may help with interpretation of results.

Problem (Step 19): Cytotoxic stimuli with a direct impact on lipids in the plasma membrane interfere with the digitonin extraction procedure, producing misleading results. 
M. Jäättelä and J. Nylandsted

Solution: LMP should be estimated using fluorescent dextran-loaded lysosomes (see Protocol: Visualizing Lysosomal Membrane Permeabilization by Fluorescent Dextran Release [Ellegaard et al. 2015]) or cathepsin immunostaining (see Protocol: A Method to Monitor Lysosomal Membrane Permeabilization by Immunocytochemistry [Groth-Pedersen et al. 2015]).

\section{RELATED TECHNIQUES}

When using treatments that influence cellular cholesterol content or have detergent-like properties (e.g., cationic amphiphilic drugs), the above method must be used with care, as such treatments may interfere with the digitonin extraction procedure. In these cases, alternative approaches should be used to estimate LMP; see Protocol: Visualizing Lysosomal Membrane Permeabilization by Fluorescent Dextran Release (Ellegaard et al. 2015) and Protocol: A Method to Monitor Lysosomal Membrane Permeabilization by Immunocytochemistry (Groth-Pedersen et al. 2015). Furthermore, in challenging conditions where the level of LMP is low because of rupture of only a few lysosomes per cell, it is not feasible to measure LMP by this method. It may instead prove advantageous to estimate LMP by transmission electron microscopy-based methods (e.g., by using BSA gold-labeled lysosomes to monitor LMP at a single-cell level [Gyrd-Hansen et al. 2006]).

\section{RECIPES}

$\boldsymbol{\beta}$-N-Acetyl-Glucosaminidase Reaction Buffer

Reagent

Final concentration

Sodium citrate buffer ( $\mathrm{pH} 4.5)$ $0.2 \mathrm{M}$

4-Methylumbelliferyl-2-acetamido-2-deoxy- $\beta$-Dglucopyranoside substrate (Sigma-Aldrich)

$300 \mu \mathrm{g} / \mathrm{mL}$

Store in aliquots at $-20^{\circ} \mathrm{C}$.

Caspase Reaction Buffer

Reagent Final concentration

HEPES

Glycerol

$100 \mathrm{~mm}$

EDTA

$20 \%$

CHAPS

$0.5 \mathrm{~mm}$

Pefabloc

$0.1 \%$

Dithiothreitol (DTT)

$0.5 \mathrm{~mm}$

Ac-DEVD-7-amino-trifluoromethylcoumarin $\quad 50 \mu \mathrm{M}$

(AFC) substrate (Enzo Life Sciences)

Prepare a stock solution that contains the first four ingredients, adjust $\mathrm{pH}$ to 7.5 , and store it at $4^{\circ} \mathrm{C}$. Immediately before use, add the last three ingredients.

Cathepsin Reaction Buffer

Reagent

Final concentration

Sodium acetate

$50 \mathrm{~mm}$

EDTA

$4 \mathrm{~mm}$

Pefabloc

$0.5 \mathrm{~mm}$

Dithiothreitol (DTT)

$8 \mathrm{~mm}$

Z-FR-AFC substrate (MP Bio)

$50 \mu \mathrm{M}$

Prepare a stock solution that contains the first two ingredients, adjust $\mathrm{pH}$ to 6.0 , and store it at $4^{\circ} \mathrm{C}$. Immediately before use, add the last three ingredients. 


\section{Digitonin Extraction Buffer}

Reagent Final concentration

Sucrose

$250 \mathrm{~mm}$

HEPES

$20 \mathrm{~mm}$

$\mathrm{KCl}$

$10 \mathrm{~mm}$

$\mathrm{MgCl}_{2}$

$1.5 \mathrm{~mm}$

EDTA

$1 \mathrm{~mm}$

$1 \mathrm{~mm}$

EGTA
$0.5 \mathrm{mM}$

Prepare a stock solution that contains the first six ingredients, adjust $\mathrm{pH}$ to 7.5 , and store it at $4^{\circ} \mathrm{C}$. Immediately before use, add the Pefablock.

\section{REFERENCES}

Ellegaard A-M, Jäättelä M, Nylandsted J. 2015. Visualizing lysosomal membrane permeabilization by fluorescent dextran release. Cold Spring Harb Protoc doi: $10.1101 / \mathrm{pdb}$.prot086173.

Foghsgaard L, Wissing D, Mauch D, Lademann U, Bastholm L, Boes M, Elling F, Leist M, Jaattela M. 2001. Cathepsin B acts as a dominant execution protease in tumor cell apoptosis induced by tumor necrosis factor. J Cell Biol 153: 999-1010.

Groth-Pedersen L, Ostenfeld MS, Hoyer-Hansen M, Nylandsted J, Jaattela M. 2007. Vincristine induces dramatic lysosomal changes and sensitizes cancer cells to lysosome-destabilizing siramesine. Cancer Res 67: $2217-2225$
Groth-Pedersen L, Jäättelä M, Nylandsted J. 2015. A method to monitor lysosomal membrane permeabilization by immunocytochemistry. Cold Spring Harb Protoc doi: 10.1101/pdb.prot086181.

Gyrd-Hansen M, Farkas T, Fehrenbacher N, Bastholm L, Hoyer-Hansen M, Elling F, Wallach D, Flavell R, Kroemer G, Nylandsted J, et al. 2006. Apoptosome-independent activation of the lysosomal cell death pathway by caspase-9. Mol Cell Biol 26: 7880-7891.

Nylandsted J, Gyrd-Hansen M, Danielewicz A, Fehrenbacher N, Lademann U, Hoyer-Hansen M, Weber E, Multhoff G, Rohde M, Jaattela M. 2004. Heat shock protein 70 promotes cell survival by inhibiting lysosomal membrane permeabilization. J Exp Med 200: 425-435. 


\section{Quantification of Lysosomal Membrane Permeabilization by Cytosolic Cathepsin and $\beta$ - $N$-Acetyl-Glucosaminidase Activity Measurements}

Marja Jäättelä and Jesper Nylandsted

Cold Spring Harb Protoc; doi: 10.1101/pdb.prot086165

\begin{tabular}{rc}
$\begin{array}{r}\text { Email Alerting } \\
\text { Service }\end{array}$ & Receive free email alerts when new articles cite this article - click here. \\
\hline $\begin{array}{r}\text { Subject } \\
\text { Categories }\end{array}$ & $\begin{array}{c}\text { Browse articles on similar topics from Cold Spring Harbor Protocols. } \\
\text { Cell Biology, general (1382 articles) } \\
\text { Preparation of Cellular and Subcellular Extracts (104 articles) }\end{array}$ \\
\hline
\end{tabular}

